\title{
Genetic structure of Plasmodium falciparum populations across the Honduras-Nicaragua border
}

Nerea Larrañaga ${ }^{1}$, Rosa E Mejía ${ }^{2}$, José I Hormaza ${ }^{1}$, Alberto Montoya ${ }^{3}$, Aida Soto ${ }^{4}$ and Gustavo A Fontecha ${ }^{5^{*}}$

\begin{abstract}
Background: The Caribbean coast of Central America remains an area of malaria transmission caused by Plasmodium falciparum despite the fact that morbidity has been reduced in recent years. Parasite populations in that region show interesting characteristics such as chloroquine susceptibility and low mortality rates. Genetic structure and diversity of P. falciparum populations in the Honduras-Nicaragua border were analysed in this study.

Methods: Seven neutral microsatellite loci were analysed in 110 P. falciparum isolates from endemic areas of Honduras $(n=77)$ and Nicaragua $(n=33)$, mostly from the border region called the Moskitia. Several analyses concerning the genetic diversity, linkage disequilibrium, population structure, molecular variance, and haplotype clustering were conducted.

Results: There was a low level of genetic diversity in P. falciparum populations from Honduras and Nicaragua. Expected heterozigosity $\left(H_{e}\right)$ results were similarly low for both populations. A moderate differentiation was revealed by the $F_{S T}$ index between both populations, and two putative clusters were defined through a structure analysis. The main cluster grouped most of samples from Honduras and Nicaragua, while the second cluster was smaller and included all the samples from the Siuna community in Nicaragua. This result could partially explain the stronger linkage disequilibrium (LD) in the parasite population from that country. These findings are congruent with the decreasing rates of malaria endemicity in Central America.
\end{abstract}

Keywords: Plasmodium falciparum, Honduras, Nicaragua, Population structure, Genetic diversity, Microsatellites

\section{Background}

In the region of the Americas, malaria still occurs in 21 countries with about $30 \%$ of inhabitants at some risk of infection and $8 \%$ at high risk. During 2011, the largest number of cases occurred in countries that share the Amazon rainforest, such as Brazil, Colombia, Peru, and Venezuela, while in the Mesoamerica subregion malaria cases are concentrated in Honduras, Guatemala and Nicaragua, in descending order of importance [1]. In those countries, less than $8 \%$ of malaria cases are caused by Plasmodium falciparum and the remaining cases are caused by Plasmodium vivax (based on data provided by National Health Ministries). Thanks to the tremendous efforts of national and international organizations, a

\footnotetext{
* Correspondence: gustavo.fontecha@unah.edu.hn

${ }^{5}$ Instituto de Investigacion en Microbiologia, Escuela de Microbiologia, UNAH, Tegucigalpa, Honduras

Full list of author information is available at the end of the article
}

reduction of more than $75 \%$ of incidence rates has been confirmed in six countries of this region between 2000 and 2011. The achievements are even greater for Costa Rica and El Salvador, which are now considered in the malaria pre-elimination phase [1].

The distribution of malaria cases caused by $P$. falciparum in Central America is limited to the coastal areas of the Caribbean, such as the Bay Islands in Honduras and the region called "Moskitia". Moskitia is a territory shared by Honduras and Nicaragua (Figure 1), with a tropical rainforest-dominant ecosystem and particular conditions concerning the epidemiology of the disease and social characteristics, such as extreme poverty, social inequity and low educational levels. This region contributes most cases of infections by P. falciparum in Central America [2]. In spite of the relative small territory of Central American countries, cultural barriers (the human population of Moskitia is mostly indigenous Miskito, with their 


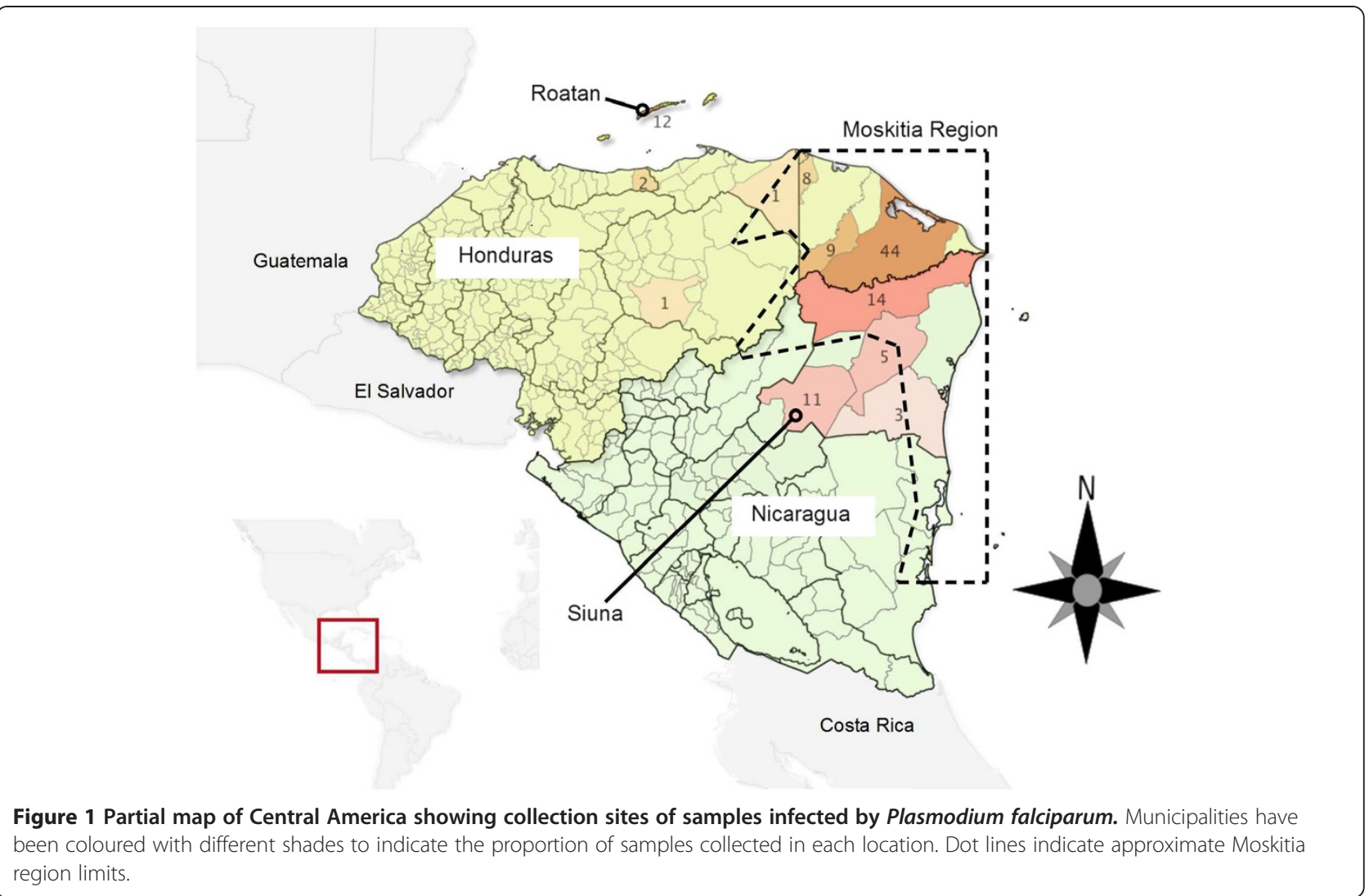

own language) and severe access problems tend to isolate Miskito communities from the rest of the society.

One of the most notable epidemiological characteristic of P. falciparum populations in Central America is the susceptibility to chloroquine (CQ) $[3,4]$, which ceased to be useful a long time ago in other regions of the world, including South America [5,6]. CQ susceptibility of the pathogen is tremendously advantageous to fight against malaria and this is partly the reason for the recent success in malaria control in Central America. However, there are some environmental and anthropogenic factors that could challenge national malaria control programmes, such as deforestation due to agricultural practices driving an increase in vector abundance, climatic change, or illegal migration of people from south to north through the Central American isthmus.

Genetic diversity indexes can be used as indicative of the adaptation and fitness of Plasmodium populations in a particular ecosystem [7]. Extensive analyses of genetic diversity of Plasmodium species have been reported worldwide in order to better understand the biology of the parasite [7-9] and the acquisition of immunity to malaria [10]. Those studies have demonstrated how especially useful it is to predict the spreading of phenotypes of interest concerning drug resistance $[9,11,12]$, and target antigens for vaccine development [13-16].
Multilocus genotyping of neutral molecular markers is one of the most frequent approaches used to determine the structure of $P$. falciparum populations. Consensus patterns of population structure have been found depending on the transmission rate in different regions $[9,17,18]$. In general terms, high genetic diversity, low linkage disequilibrium (LD) and weak population differentiation are typical of high transmission areas [19]. Highly endemic areas, such as sub-Saharan Africa, also show more frequent outcrossing of isolates, leading to panmictic structures of parasites with abundant genotypes. In the Americas, the opposite genetic scenario seems more likely: lower genetic diversity, high levels of LD and well-defined population structure [20].

In the Americas, population analyses of $P$. falciparum using neutral microsatellites or simple sequence repeats (SSR) have been reported from South America. Most of the results confirm that limited genetic diversity, significant LD, and gene flow are common for Brazil, Peru, Colombia, and Bolivia parasite populations [5,17,20-23]. In Central America, a limited number of studies on molecular techniques [24], drug resistance [3,4,25] and genetic diversity based on conserved genes $[13,26]$ of P. falciparum are available, and mostly from Honduras. However, genetic analyses of populations of this parasite based on neutral microsatellites in Central America have 
not been reported so far. Taking into account recent changes in the demography and epidemiology of malaria in this region, in this work the population structure and genetic diversity of $P$. falciparum was assessed in $11 \mathrm{mu}-$ nicipalities from Honduras and Nicaragua using seven SSR neutral markers.

\section{Methods}

\section{Parasite samples}

One-hundred and ten human blood samples from Honduras and Nicaragua areas with endemic malaria falciparum transmission were analysed. Eighty-three (75.45\%) of those samples were taken from patients living in the Moskitia region. Seventy-seven samples were collected from seven municipalities of Honduras, and 33 from four municipalities of Nicaragua (Figure 1). Twelve of 77 samples from Honduras were collected in the Caribbean island of Roatan while the rest of samples were collected in the continental territory. In Honduras, samples were collected between 2009 and 2012 in national health care centres after informed consent from patients that sought medical attention. Scientific approval and ethical clearance was obtained from the Ethics Board Committee of the Hearth-Lung National Institute, Ministry of Health of Honduras. In Nicaragua, samples were collected from patients attending routine medical diagnosis of malaria, with no initial intent to be used in research. Samples were processed without personal identifiers or hospital record numbers to avoid the risk of future re-identification of individuals. The PAHO local Office at Nicaragua and National health authorities approved this process.

All patients showed symptoms typical of malaria at the time of enrolment. Filter paper was used to collect one drop of blood from each patient for malaria surveillance purposes. Diagnosis of $P$. falciparum infections were carried out by experienced microscopists, and molecular confirmation of the species was obtained through PCR amplification of the $18 \mathrm{Sr}$ gene according to Singh et al. [27]. Three P. falciparum isolates from sub-Saharan Africa and five universally known reference clones (3D7, Dd2, HB3, 7G8 and K1) were included in this study as an outgroup and amplification controls.

\section{Microsatellite genotyping}

DNA from $P$. falciparum-positive filter paper blood spots was extracted using a Chelex-based method [28]. The following neutral SSR loci were amplified (chromosome location in parentheses) according to previously described protocols: TA1 (6), Poly- $\alpha$ (4), PfPK2 (12), TA109 (6), 2490 (10), [17], C2M34 (2) and C3M69 (2) [12]. Forward primers were labelled with a fluorescent dye on the $5^{\prime}$-end and PCR products were detected and size measured with a Beckman Coulter CEQ $^{\text {in }} 8000$ capillary DNA analysis system. Samples were denaturalized at $90^{\circ} \mathrm{C}$ for 120 seconds, injected at $2.0 \mathrm{kV}$, 30 seconds, and separated at $6.0 \mathrm{kV}$ for $35 \mathrm{~min}$. Water was used as negative control against contamination in each run and each PCR reaction was repeated at least twice to ensure the reproducibility of the results. Since Plasmodium parasites are haploid organisms during most of their life cycle, except for a brief period after fertilization inside the gut of the female Anopheles, each allele obtained in the pherogram would represent a different clone of the parasite and in single clone infections, one allele would be expected per locus in each samples. In those cases when a secondary peak was observed in the chromatogram, the height of the secondary peak was measured. If the height of the minor peak was lower than $30 \%$ of the predominant peak they were considered as single clone infections [7] and, consequently, all the calculations were performed taking into account only the predominant allele (more intense PCR product) when two peaks were present.

\section{Data analysis}

Genetic diversity parameters were calculated for the entire population and for two subpopulations (Honduras and Nicaragua) independently using ARLEQUIN version 3.5 software [29] by determining the number of alleles per locus $(A)$, allelic richness $\left(R_{s}\right)$, expected heterozigosity $\left(H_{e}\right)$, allele frequencies and the number of haplotypes $(h)$. Three of these parameters $\left(A, H_{e}\right.$ and allele frequencies) were used to indicate the level of polymorphism in the loci and determine the diversity of the populations. $H_{e}$ was calculated as $H e=\frac{n}{n-1}\left(1-\sum_{i=1}^{n} P_{i}^{2}\right)$, where $n$ is the number of isolates and $\rho_{i}$ is the frequency of $i^{\text {th }}$ allele.

Since $A$ is strongly dependent on sample size and different number of isolates were analysed in the two countries (77 in Honduras vs 33 in Nicaragua), it was necessary to normalize the data. For that, the allelic richness $\left(R_{s}\right)$ was calculated using FSTAT version 2.9.3 software, fixed as the smallest number of individuals typed for a locus in a sample.

The ARLEQUIN software was also used to estimate population differentiation using the Wright's pair-wise fixation index $F_{S T}$, which is a pair-wise distance measurement used to calculate the average $F$ statistics over all loci according to the number of different alleles between haplotypes [30].

Multilocus linkage disequilibrium ( $\mathrm{LD}=$ non-random association of alleles among loci) was measured using the Standardized Index of Association $\left(I_{A}^{S}\right)$; both $I_{A}^{S}$ and variance of data were calculated using the program LIAN version 3.5 [31]. $I_{A}^{S}$ was calculated as follows: 
$\left(V_{D} / V_{e}-1\right) /(\mathrm{n}-1)$ assuming a null hypothesis of complete linkage equilibrium $\left(I_{A}^{S}=0\right)$, where $\mathrm{V}_{\mathrm{D}}$ is the variance of the number of alleles shared between all pairs of haplotypes observed in the population, $V_{e}$ is the variance expected under linkage equilibrium, and $n$ is the number of loci examined.

To establish the structure of the populations according to geographic origin, Structure version 2.3.3 software was used. This software assigns probable individual haplotypes to multiple clusters $(K)$ relying on the allele frequencies at each locus, assuming that within populations, the loci are at Hardy-Weinberg equilibrium, and linkage equilibrium [32]. An admixture option was used. To choose the best value of $K$, five independent replicates were run for 100,000 steps, after a burn-in period of 10,000 steps, and the mean log likelihoods in each run were compared. The most likely number of populations was calculated by the higher number in the rate of change for $K(\Delta K)$ [33]. The structure of $P$. falciparum subpopulations was confirmed by analysis of molecular variance (AMOVA) [34]. Similarity between haplotypes was examined by creating a similarity matrix with Dice's coefficient to construct a UPGMA (Unweighted pair group method with arithmetic mean) dendrogram using NTSYSpc version $2.11 \mathrm{f}$ software [35].

\section{Results and discussion}

This study included $110 \mathrm{P}$. falciparum isolates from 11 communities located in Honduras and Nicaragua, mostly from the Moskitia region across the border between both countries (Figure 1). This region is characterized by a low to moderate rate of malaria transmission caused by $P$. falciparum compared to other geographic regions such as Africa or Southeast Asia. Seven neutral microsatellite loci located on five chromosomes and widely scattered in the genome of $P$. falciparum were analysed. These and other SSR markers have been used to analyse the genetic structure of $P$. falciparum populations from almost every malarial region in the world, including Africa [17,36,37], Southeast Asia [8,18,38,39], Oceania [7], and South America [5,20,21]. However, this is the first reported study of the genetic structure of $P$. falciparum involving analysis of microsatellite loci in isolates from the Moskitia region in Central America and the comparison of population structure between parasites from Honduras and Nicaragua.

\section{Genetic diversity}

Of the 110 isolates, data for all seven loci were obtained for $88(80 \%)$. For $16(14.5 \%)$ isolates allelic data were obtained for 6 loci; and the remaining 6 (5.5\%) isolates failed to amplify 2 loci. Most of the isolates analysed (99.6\%), revealed one single peak in the chromatogram but three isolates from Honduras showed two peaks for one locus each. A full description of allele sizes, missing data and mixed-clone infections is given as Additional file 1.

Number and frequencies of SSR alleles were calculated (Table 1). Allele sizes reported in this study ranged within the expected according to most of previous reports with two exceptions: Poly- $\alpha$ and TA109 loci showed much longer allele sizes in isolates from Peru [40] and Kenya [41], respectively. The number of alleles per locus in the total population was low and varied from one (TA1) to five alleles (Poly- $\alpha$, C3M69) (Table 1) ranging from two to five alleles in the samples taken in Honduras and from one to four in the samples taken in Nicaragua. There were no significant differences in the mean number of alleles per SSR locus between the

Table 1 Allelic frequencies at seven microsatellite loci

\begin{tabular}{|c|c|c|c|c|c|}
\hline Locus & Allele & $\begin{array}{l}\text { Honduras } \\
(n=77)\end{array}$ & Frequency & $\begin{array}{l}\text { Nicaragua } \\
(\mathrm{n}=33)\end{array}$ & Frequency \\
\hline \multirow[t]{6}{*}{ TA1 } & 141 & 61 & 0.79 & 19 & 0.58 \\
\hline & 144 & 11 & 0.14 & - & - \\
\hline & 147 & 1 & 0.01 & 1 & 0.03 \\
\hline & 169 & - & - & 13 & 0.39 \\
\hline & 190 & 3 & 0.04 & - & - \\
\hline & $\mathrm{MD}$ & 1 & 0.01 & - & - \\
\hline \multirow[t]{5}{*}{ POLY- a } & 141 & 3 & 0.04 & 13 & 0.39 \\
\hline & 169 & 1 & 0.01 & - & - \\
\hline & 173 & 6 & 0.08 & - & - \\
\hline & 179 & 66 & 0.86 & 20 & 0.61 \\
\hline & 181 & 1 & 0.01 & - & - \\
\hline \multirow[t]{5}{*}{ PFPK2 } & 131 & 1 & 0.01 & - & - \\
\hline & 162 & 24 & 0.31 & 3 & 0.09 \\
\hline & 189 & 7 & 0.09 & 12 & 0.36 \\
\hline & 195 & 45 & 0.58 & 17 & 0.52 \\
\hline & $\mathrm{MD}$ & - & - & 1 & 0.03 \\
\hline \multirow[t]{3}{*}{ TA109 } & 189 & 49 & 0.64 & 24 & 0.73 \\
\hline & 201 & 25 & 0.32 & 8 & 0.24 \\
\hline & $\mathrm{MD}$ & 3 & 0.04 & 1 & 0.03 \\
\hline \multirow[t]{2}{*}{2490} & 80 & 2 & 0.03 & - & - \\
\hline & 83 & 74 & 0.96 & 33 & 1 \\
\hline \multirow[t]{3}{*}{ C2M34 } & 225 & 55 & 0.71 & 27 & 0.76 \\
\hline & 227 & 9 & 0.12 & - & - \\
\hline & $\mathrm{MD}$ & 13 & 0.17 & 6 & 0.08 \\
\hline \multirow[t]{5}{*}{ C3M69 } & 125 & 20 & 0.26 & 9 & 0.27 \\
\hline & 137 & 8 & 0.10 & 1 & 0.03 \\
\hline & 139 & 44 & 0.57 & 9 & 0.27 \\
\hline & 141 & - & - & 13 & 0.40 \\
\hline & $\mathrm{MD}$ & 5 & 0.06 & 1 & 0.03 \\
\hline
\end{tabular}

$\mathrm{MD}=$ missing data 
Table 2 Allelic diversity at seven microsatellite loci of Plasmodium falciparum in Honduras and Nicaragua

\begin{tabular}{|c|c|c|c|c|c|c|}
\hline \multirow[t]{2}{*}{ Locus } & \multicolumn{2}{|l|}{$A^{*}\left(R_{s}^{* *}\right)$} & \multicolumn{4}{|c|}{ Expected heterozygosity $\left(\mathrm{H}_{\mathrm{e}}\right)$ (s.d.) } \\
\hline & $\mathrm{HN}(n=77)$ & NIC $(n=33)$ & $\mathrm{HN}$ & NIC & Mean (s.d.) & Tot. Het. \\
\hline TA1 & $4(3.52)$ & $3(2.97)$ & 0.34 & 0.53 & $0.43(0.14)$ & 0.44 \\
\hline POLY-A & $5(4.08)$ & $2(2)$ & 0.26 & 0.49 & $0.38(0.16)$ & 0.37 \\
\hline PFPK2 & $4(3.58)$ & $3(3)$ & 0.56 & 0.59 & $0.57(0.02)$ & 0.59 \\
\hline TA109 & $2(2)$ & $2(2)$ & 0.45 & 0.39 & $0.42(0.05)$ & 0.43 \\
\hline 2490 & $2(1.83)$ & $1(1)$ & 0.05 & 0 & $0.03(0.04)$ & 0.04 \\
\hline C2M34 & $2(2)$ & $1(1)$ & 0.25 & 0 & $0.12(0.17)$ & 0.18 \\
\hline C3M69 & $3(3)$ & $4(3.98)$ & 0.54 & 0.70 & $0.62(0.11)$ & 0.65 \\
\hline Mean & $3.14(2.86)$ & $2.29(2.28)$ & $0.35(0.18)$ & $0.38(0.28)$ & $0.37(0.02)$ & 0.38 \\
\hline s.d. & $1.15(0.91)$ & $1.11(1.10)$ & & & & \\
\hline
\end{tabular}

${ }^{*} \mathrm{~A}=$ Numbers of different alleles within each population.

** $\mathrm{R}_{\mathrm{S}}=$ allelic richness.

samples taken from those two countries (Table 2) calculated by a $t$ test. Normalized allelic richness $\left(R_{S}\right)$ showed a similar pattern, ranging from 1.83 to 4.08 in Honduras, and from 1 to 3.98 in Nicaragua.

The number of exclusive alleles observed in only one of the two countries (Honduras vs Nicaragua) ranged from zero (for TA109 locus) to three (Poly- $\alpha$ ). In general terms, the number of alleles per locus tends to be higher in areas of high endemicity, and lower in areas of low or moderate endemicity $[18,40]$. In this case, because of its low number of alleles, the Moskitia region could be comparable to regions of similar epidemiology, such as Amazonia [17], Malaysia [18] and Philippines [42] with an unstable pattern of malaria transmission [26], and where allele diversity remains almost unchanged in time [43]. A different scenario can be observed in regions

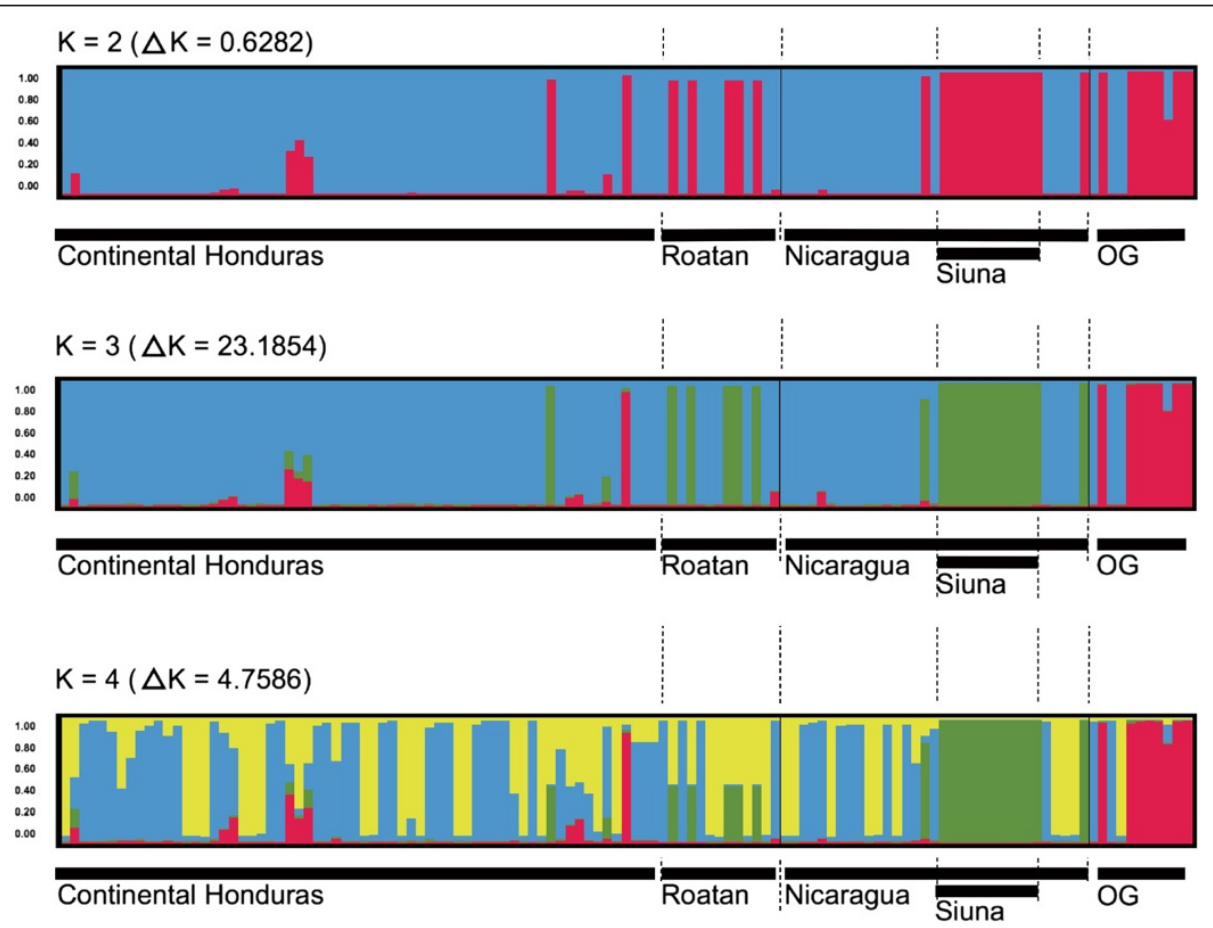

Figure 2 Bayesian clustering of 110 isolates assigned to $\mathrm{K}$ populations based on seven SSR markers. Each bar represents the proportion of each haplotype with ancestry in the defined clusters, each cluster being indicated by a different colour. OG: outgroup of reference clones parasites with an African origin. 
with high endemicity such as Sub-Saharan Africa, with allele numbers ranging from 5.3 [44] to 13.5 [37] for similar loci.

The small variation in allele numbers between countries was further evaluated by expected heterozigosity $\left(\mathrm{H}_{\mathrm{e}}\right) . \mathrm{H}_{\mathrm{e}}$ was similar for both populations in Honduras $(0.35 \pm 0.18)$, and Nicaragua $(0.38 \pm 0.28)$ (Table 2), in spite of the difference in the number of samples (77 vs 33 , respectively).

Low estimates of expected heterozygosities found for Central American P. falciparum populations are comparable with other studies based on neutral microsatellite loci in South America: Brazil (0.14-0.62) [39,45], and Peru (0.34-0.62) [40]. $H_{e}$ values revealed to be lower than those found in other countries with higher endemicity, such as: Vietnam (0.52-0.91), three West African countries (0.78-0.96) [46], Nigeria (0.83-0.92), Sudan (0.67-0.90) and South Africa (0.76-0.96) [45]. This result also indicates that heterozygosity levels in Central American populations are compatible with those expected in areas of a proportional lower malaria transmission with no frequent outcrossing.

\section{Population structure}

The $\mathrm{F}_{\mathrm{ST}}$ coefficient was estimated for both subpopulations using seven microsatellite loci. $\mathrm{F}_{\mathrm{ST}}$ is based on the differences in allele frequencies in each population. The number of isolates used to calculate $\mathrm{F}_{\mathrm{ST}}$ between Honduras and Nicaragua was 77 and 33, respectively. Values close to zero suggest no frequency differences, and values similar to 1.0 indicate completely fixed differences without shared alleles. $\mathrm{F}_{\mathrm{ST}}$ index measuring Honduras-Nicaragua interpopulation variance in allele frequencies was 0.14 . A qualitative interpretation of $\mathrm{F}_{\mathrm{ST}}$ values has been suggested [47], where values between $0-0.05$ could indicate low genetic differentiation among populations; values between 0.050.15 could indicate moderate differentiation; values ranging from $0.15-0.25$ could indicate great differentiation; and values higher than 0.25 could indicate very great differentiation. Based on this not universally accepted classification, the Honduras parasite population would differ moderately from the Nicaragua population. A recent publication has described the genetic diversity of $P$. falciparum populations in Malaysia through a deep sequencing approach [9]. These authors show that the fixation indexes and parasite population structure tend to increase where the malaria transmission is low or patchy. That patchy population pattern could be occurring in Nicaragua, where the malaria transmission is descending faster than it does in Honduras.

In order to find out the reason for the moderate differentiation between subpopulations, a clustering approach was undertaken using the Structure software. This Software uses a Bayesian analysis to infer the most likely number of populations $(K)$, and measures the probability that individual parasites belong to each of these $K$ populations [32]. This analysis defined three putative clusters $(\Delta K=23.19)$ (Figure 2$)$. The first cluster included most of samples from both countries (Honduras and Nicaragua). The second cluster grouped all the 11 isolates collected in the Nicaraguan community of Siuna, five isolates from Roatan Island, one isolate from Wampusirpi (Honduran Moskitia), one from Rosita, and one from Prinzapolka (Nicaraguan Moskitia). The third cluster the three outgroup isolates of African origin and P. falciparum reference clones. This analysis indicates a weak population structure in parasites isolated from continental Honduras and Nicaragua, with the exception of samples grouped into the second cluster. Therefore, Siuna isolates could explain the moderate differentiation between Honduras and Nicaragua samples. Although Siuna is part of the municipalities located in the Nicaraguan region called RAAN (Autonomous Region of North Atlantic) with the highest

Table 3 Haplotypes frequency estimation of Plasmodium falciparum in Honduras and Nicaragua

\begin{tabular}{|c|c|c|c|c|}
\hline \multirow[t]{2}{*}{ Haplotype } & \multicolumn{2}{|c|}{ Honduras $(n=77)$} & \multicolumn{2}{|c|}{ Nicaragua $(n=33)$} \\
\hline & $\begin{array}{l}\text { Number of } \\
\text { samples }\end{array}$ & Frequency & $\begin{array}{l}\text { Number of } \\
\text { samples }\end{array}$ & Frequency \\
\hline I & 22 & 0.29 & 9 & 0.27 \\
\hline$\|$ & 2 & 0.03 & 0 & 0 \\
\hline III & 1 & 0.01 & 1 & 0.03 \\
\hline IV & 2 & 0.03 & 0 & 0 \\
\hline V & 6 & 0.08 & 0 & 0 \\
\hline VI & 1 & 0.01 & 0 & 0 \\
\hline VII & 7 & 0.09 & 1 & 0.03 \\
\hline VIII & 1 & 0.01 & 0 & 0 \\
\hline IX & 5 & 0.06 & 6 & 0.18 \\
\hline$x$ & 1 & 0.01 & 0 & 0 \\
\hline$X I$ & 1 & 0.01 & 0 & 0 \\
\hline XII & 1 & 0.01 & 0 & 0 \\
\hline XIII & 5 & 0.06 & 0 & 0 \\
\hline XIV & 1 & 0.01 & 0 & 0 \\
\hline$x V$ & 1 & 0.01 & 0 & 0 \\
\hline $\mathrm{XVI}$ & 7 & 0.09 & 2 & 0.06 \\
\hline XVII & 1 & 0.01 & 0 & 0 \\
\hline XVIII & 6 & 0.08 & 0 & 0 \\
\hline XIX & 1 & 0.01 & 0 & 0 \\
\hline$X X$ & 2 & 0.03 & 0 & 0 \\
\hline XXI & 1 & 0.01 & 0 & 0 \\
\hline XXII & 1 & 0.01 & 0 & 0 \\
\hline XXIII & 1 & 0.01 & 1 & 0.03 \\
\hline XXIV & 0 & 0 & 1 & 0.03 \\
\hline$X X V$ & 0 & 0 & 12 & 0.36 \\
\hline
\end{tabular}


malaria incidence in Nicaragua, its human population is ethnically different from the inhabitants of the neighbor region of Moskitia and belong to different language cultures. This social difference and the almost inexistent access roads between municipalities could indicate historical separation of human communities and, as a consequence, barriers for gene flow and parasite migration, as suggested by similar studies in other regions [7].

Confirming this, a haplotype $(h)$ analysis defined 25 haplotypes in the whole population (Table 3). Only two haplotypes did not include isolates from Honduras, whilst 17 haplotypes lacked representatives from Nicaragua, which could be a consequence of a lower number of samples from this country. It is noteworthy that haplotype I was the most frequent in both countries: $29 \%$ in Honduras and $27 \%$ in Nicaragua, and six haplotypes included isolates from both countries. Based on this evidence it is possible to suggest that most parasite haplotypes circulating through Honduras and Nicaragua are not geographically separated in spite of the political border. Once again, the most interesting finding was the exclusive presence of haplotype XXV in the Siuna region with 11 sampled individuals (Figure 3), which could be explained by different, non-mutually exclusive reasons such as an inbreeding phenomenon, a transient clonal expansion of a founder infection.
A UPGMA dendrogram was constructed to further evaluate similarity between subpopulations. The tree obtained supports the Bayesian clustering pattern shown before. Figure 4 illustrates how isolates from continental Honduras and Nicaragua form an interspersed and poorly differentiated pool of branches. However, the outgroup genotypes and the Siuna population separated into two well-differentiated clusters. A coloured diagram of Structure results (for three populations) with an identical ordering of isolates has been placed on the right side of the dendrogram, aiming to better visualize the population structure. Interestingly, some individuals belonging to the population of Roatan Island reveal a moderately strong cluster placed in the same population as the Siuna samples by the Structure result.

Furthermore, an analysis of molecular variance (AMOVA) was used to assess the population structure of P. falciparum in Central America by partitioning variation among and within the Honduras and Nicaragua subpopulations. Results of AMOVA indicated that most of the genetic variation among parasites is contained within populations $(86 \%)$, and only $14 \%$ of variation was explained by comparing subpopulations, suggesting a relative free gene flow across the region. This variation of $14 \%$ is consistent with the $\mathrm{F}_{\mathrm{ST}}$ index between populations described before. Similar results were reported for

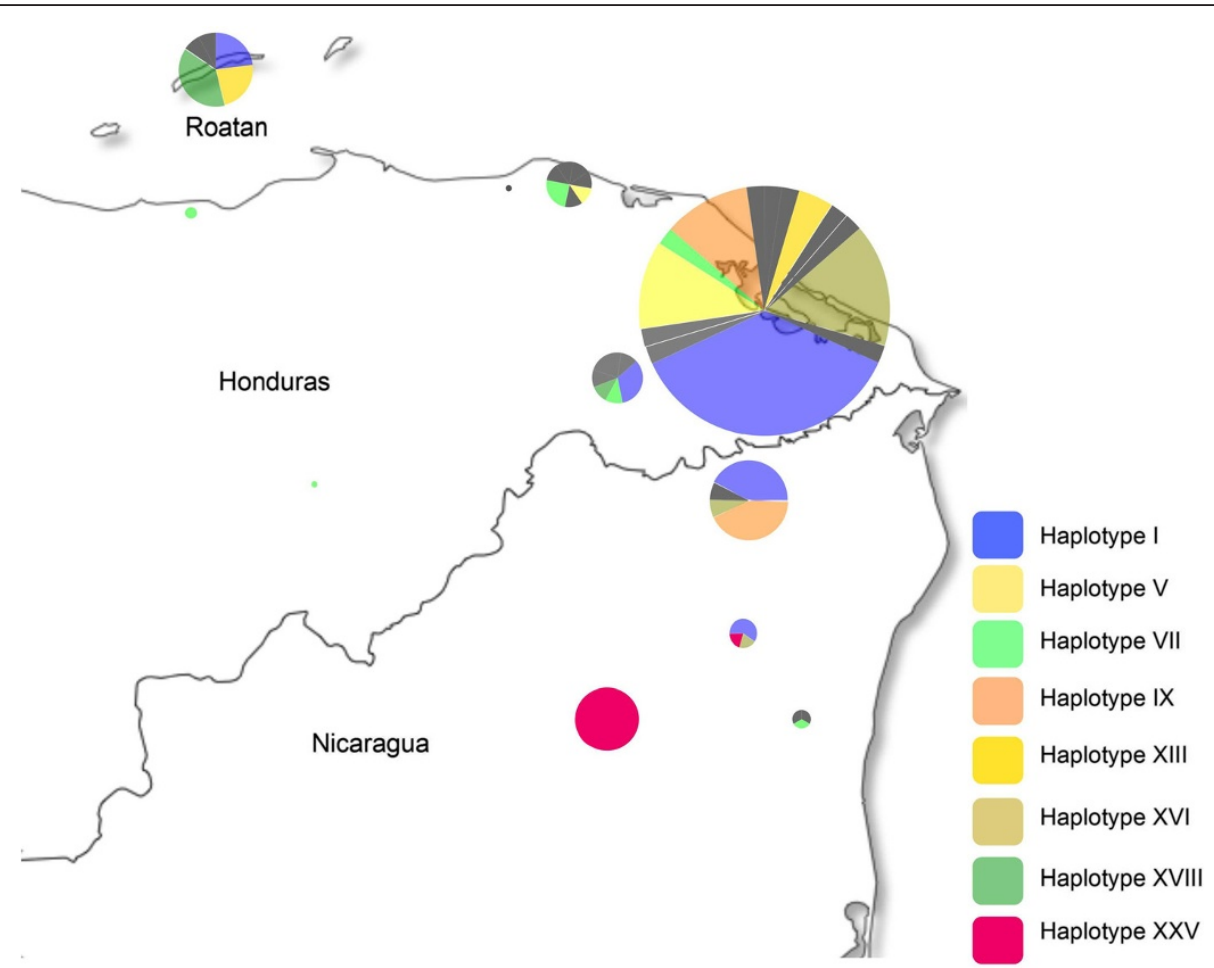

Figure 3 Haplotype distribution by geographic region. Less common haplotypes are shaded in grey. Circle sizes indicate the number of isolates collected in those communities. 


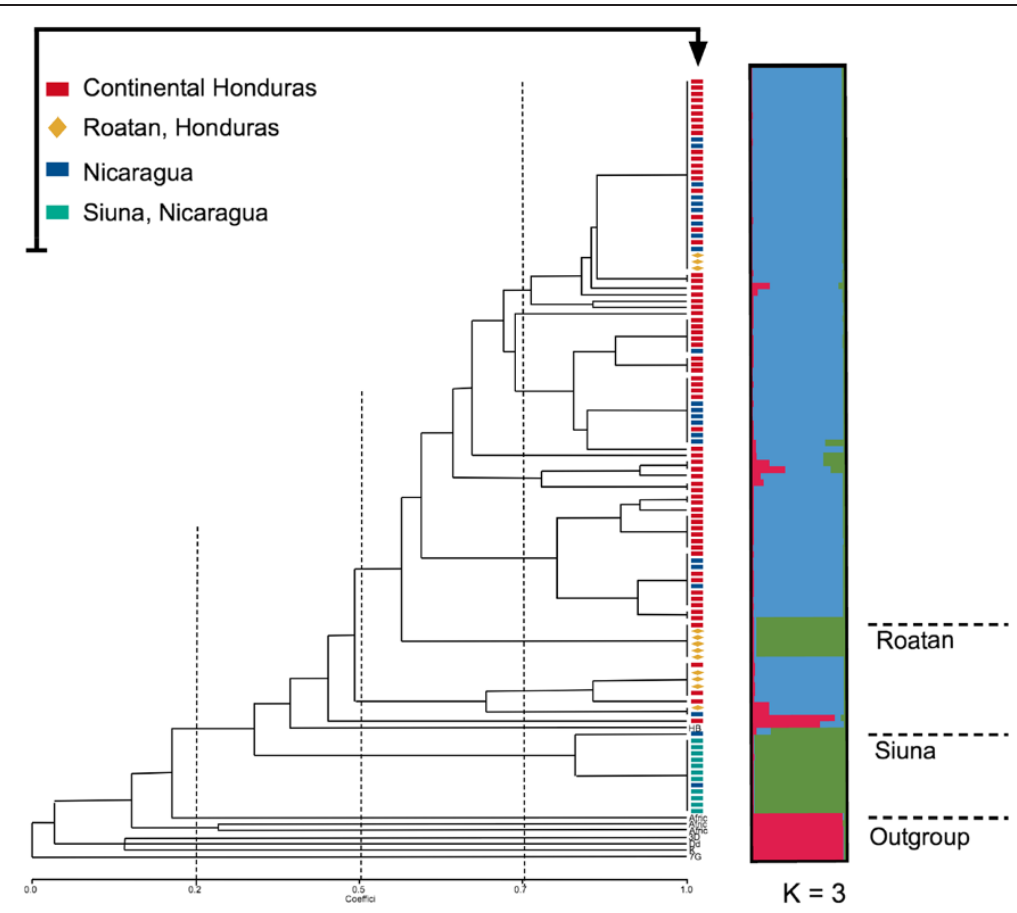

Figure 4 UPGMA dendrogram showing the relationships between Plasmodium falciparum isolates and a putative population structure. Isolates are coloured according to geographic location in the dendrogram.

South American parasite populations, where most of the diversity was also found within locations [23]. In addition, a second AMOVA analysis comparing the two populations described by the Structure software was carried out. In this case, the results showed high differentiation $\left(\mathrm{F}_{\mathrm{ST}}=0.56\right)$ between both populations, where $55.64 \%$ of the variance was explained between populations and $44.36 \%$ within populations.

\section{Multilocus linkage disequilibrium}

Existence of multilocus linkage disequilibrium (LD) was calculated for the entire population as a whole, and separately for each subpopulation using the standardized index of association $\left(\mathrm{I}_{\mathrm{S}}^{\mathrm{A}}\right)$. The Nicaragua parasite subpopulation showed a significantly higher LD value than the Honduran subpopulation (Table 4). In general terms a stronger LD corresponds to low endemicity and vice versa $[8,17]$. In this case, the stronger LD revealed in the Nicaraguan subpopulation could be due to a lower transmission intensity where mixed-clone infections were not found and recombination between parasite genomes is less probable [48,49]. A higher LD value of parasites from Nicaragua, added to an exclusive haplotype in Siuna, suggests a high level of ongoing inbreeding in that population.

A second LD test was also performed but including unique haplotypes for each population only (Table 4). In the parasite populations from Honduras LD maintained similar (0.0483 vs 0.0716), however this was not the case for Nicaraguan isolates including 11 isolates from Siuna. LD was considerably reduced from 0.2623 to 0.0886 when only unique haplotypes from Nicaragua were analyzed. This result reinforces the hypothesis that only a small population of parasites from Nicaragua behaves as a residual focus in an area of declining endemicity.

\section{Conclusions}

Genetic diversity indexes and population structure of $P$. falciparum were determined in Honduras and Nicaragua using seven SSR neutral loci. This approach is an

Table 4 Linkage desequilibrium analysis for each Plasmodium falciparum population

\begin{tabular}{ccccccc}
\hline Population & $\mathbf{V}_{\mathbf{D}}$ & $\mathbf{V}_{\mathbf{e}}$ & $\mathbf{I}_{\mathbf{A}}^{\mathbf{s}}$ & $\begin{array}{c}\text { Var } \\
\left.\mathbf{V}_{\mathbf{D}}\right)\end{array}$ & \multicolumn{2}{c}{$\begin{array}{c}\text { Unique haplotypes only } \\
\text { Isolates (n) }\end{array}$} \\
\hline Honduras and Nicaragua & 2.4 & 1.5 & 0.1051 & 0.008 & - & 34 \\
Honduras & 1.9 & 1.5 & 0.0483 & 0.012 & 0.072 \\
Nicaragua & 3.6 & 1.4 & 0.2623 & 0.009 & 13 & 0.088 \\
\hline
\end{tabular}

$V_{D}=$ variance; $V_{e}=$ expected variance if linkage equilibrium exist; $I_{A}^{S}=$ Standardized Index of Association; $\operatorname{Var}\left(V_{D}\right)=$ null hypothesis; $V_{D}=V_{e}$. 
important tool to better understand the epidemiologic factors that need to be focused in order to control infections and to anticipate emergence of drug resistance. Honduras and Nicaragua are two of the few remaining countries in the world where $P$. falciparum and $P$. vivax are still susceptible to CQ and sulphadoxine-pyrimethamine [3,4]. This phenomenon has not been clearly explained so far, but several authors have theorized about a possible correlation between population structure and emergence/spread of drug resistance in different regions [18,42,50]. This study has demonstrated gene flow and lack of significant genetic structure in P. falciparum populations between Honduras and Nicaragua when neutral markers are analysed. In consequence, those results could contribute to the untangling of the reasons for drug susceptibility and the potential for drug-resistant mutation emergence in Central America during malaria control and elimination stages.

\section{Additional file}

Additional file 1: Microsatellite allele sizes for Plasmodium falciparum populations from Honduras, Nicaragua and reference clones.

\section{Abbreviations \\ Dd2: Plasmodium falciparum strain collected in Indochina/Laos; \\ HB3: Plasmodium falciparum strain collected in Honduras; 7G8: Plasmodium falciparum strain collected in Brazil; K1: Plasmodium falciparum strain collected in Thailand; 3D7: Plasmodium falciparum clone from NF54, which was isolated from a patient who lived near the airport in Amsterdam, the Netherlands. The origin of the infection is unknown.}

\section{Competing interests}

The authors declare that they have no competing interests.

\section{Authors' contributions}

GF and NL carried out the DNA extraction and performed molecular experiments. GF, NL and $\mathrm{H}$ drafted the manuscript and all authors read and edited the manuscript. RM, AM, and AS participated in sample collection and microscopic analyses coordination. GF, NL, and $\mathrm{IH}$ conceived the study and participated in its design and coordination and helped to draft the manuscript. All authors read and approved the final manuscript.

\section{Acknowledgements}

We would like to thank Dr Udhayakumar Venkatachalam and his research team at Malaria Branch, CDC, for technical assistance and providing amplification protocols and DNA of reference clones. DNA from reference clones was also provided by Irina Jovel from Karolinska Institute, Sweden. The financial support for this work was provided by CSIC (I-COOP0071). Complementary funds were provided by Direccion de Investigacion Cientifica - UNAH

\section{Author details}

${ }^{1}$ Instituto de Hortofruticultura Subtropical y Mediterránea La Mayora (IHSM-UMA-CSIC), Algarrobo-Costa, Málaga 29750, Spain. ²National Malaria Laboratory, Health Ministry, Tegucigalpa, Honduras. ${ }^{3}$ National Center for Diagnosis and Reference, Health Ministry, Managua, Nicaragua. ${ }^{4}$ Panamerican Health Organization, Managua, Nicaragua. ${ }^{5}$ Instituto de Investigacion en Microbiologia, Escuela de Microbiologia, UNAH, Tegucigalpa, Honduras.

Received: 16 August 2013 Accepted: 2 October 2013

Published: 4 October 2013

\section{References}

1. WHO: World Malaria Report: 2012. Geneva: World Health Organization; 2012.

2. Honduras Ministry of Health: Malaria situation in Honduras 2010. Tegucigalpa: National Malaria Programme; 2011.

3. Jovel IT, Mejia RE, Banegas E, Piedade R, Alger J, Fontecha G, Ferreira PE, Veiga MI, Enamorado IG, Bjorkman A, Ursing J: Drug resistance associated genetic polymorphisms in Plasmodium falciparum and Plasmodium vivax collected in Honduras, Central America. Malar J 2011, 10:376.

4. Mejia Torres RE, Banegas El, Mendoza M, Diaz C, Bucheli ST, Fontecha GA, Alam MT, Goldman I, Udhayakumar V, Zambrano JO: Efficacy of chloroquine for the treatment of uncomplicated Plasmodium falciparum malaria in Honduras. Am J Trop Med Hyg 2013, 88:850-854.

5. Vieira PP, Ferreira MU, Alecrim MG, Alecrim WD, da Silva LH, Sihuincha MM, Joy DA, Mu J, Su XZ, Zalis MG: pfcrt polymorphism and the spread of chloroquine resistance in Plasmodium falciparum populations across the Amazon Basin. J Infect Dis 2004, 190:417-424.

6. Ruebush TK 2nd, Zegarra J, Cairo J, Andersen EM, Green M, Pillai DR, Marquino W, Huilca M, Arevalo E, Garcia C, Solary L, Kain KC: Chloroquine-resistant Plasmodium vivax malaria in Peru. Am J Trop Med Hyg 2003, 69:548-552.

7. Schultz L, Wapling J, Mueller I, Ntsuke PO, Senn N, Nale J, Kiniboro B, Buckee CO, Tavul L, Siba PM, Reeder JC, Barry AE: Multilocus haplotypes reveal variable levels of diversity and population structure of Plasmodium falciparum in Papua New Guinea, a region of intense perennial transmission. Malar J 2010, 9:336.

8. Pumpaibool T, Arnathau C, Durand P, Kanchanakhan N, Siripoon N, Suegorn A, Sitthi-Amorn C, Renaud F, Harnyuttanakorn P: Genetic diversity and population structure of Plasmodium falciparum in Thailand, a low transmission country. Malar J 2009, 8:155.

9. Manske M, Miotto O, Campino S, Auburn S, Almagro-Garcia J, Maslen G, O'Brien J, Djimde A, Doumbo O, Zongo I, Ouedraogo JB, Michon P, Mueller I, Siba P, Nzila A, Borrmann S, Kiara SM, Marsh K, Jiang H, Su XZ, Amaratunga $C$, Fairhurst $R$, Socheat $D$, Nosten F, Imwong M, White $N J$, Sanders M, Anastasi E, Alcock D, Drury E, Oyola S, Quail MA, Turner DJ, Ruano-Rubio V, Jyothi D, Amenga-Etego L, Hubbart C, Jeffreys A, Rowlands K, Sutherland C, Roper C, Mangano V, Modiano D, Tan JC, Ferdig MT, Amambua-Ngwa A, Conway DJ, Takala-Harrison S, Plowe CV, Rayner JC, Rockett KA, Clark TG, Newbold Cl, Berriman M: Analysis of Plasmodium falciparum diversity in natural infections by deep sequencing. Nat 2012, 487:375-379.

10. Buckee CO, Bull PC, Gupta S: Inferring malaria parasite population structure from serological networks. Proc Biol Sci 2009, 276:477-485.

11. Griffing SM, Mixson-Hayden T, Sridaran S, Alam MT, McCollum AM, Cabezas C, Marquino Quezada W, Barnwell JW, De Oliveira AM, Lucas C, Arrospide N, Escalante AA, Bacon DJ, Udhayakumar V: South American Plasmodium falciparum after the malaria eradication era: clonal population expansion and survival of the fittest hybrids. PLoS One 2011, 6:e23486.

12. Alam MT, de Souza DK, Vinayak S, Griffing SM, Poe AC, Duah NO, Ghansah A, Asamoa K, Slutsker L, Wilson MD, Barnwell JW, Udhayakumar V, Koram KA: Selective sweeps and genetic lineages of Plasmodium falciparum drug -resistant alleles in Ghana. J Infect Dis 2011, 203:220-227.

13. Lopez AC, Ortiz A, Coello J, Sosa-Ochoa W, Torres RE, Banegas El, Jovel I, Fontecha GA: Genetic diversity of Plasmodium vivax and Plasmodium falciparum in Honduras. Malar J 2012, 11:391.

14. Singh JP, Verma S, Bhattacharya PR, Srivastava N, Dash AP, Biswas S: Plasmodium falciparum circumsporozoite protein: epidemiological variations among field isolates prevalent in India. Trop Med Int Health 2009, 14:957-966.

15. Tanabe K, Mita T, Palacpac NM, Arisue N, Tougan T, Kawai S, Jombart T, Kobayashi F, Horii T: Within-population genetic diversity of Plasmodium falciparum vaccine candidate antigens reveals geographic distance from a Central sub-Saharan African origin. Vaccine 2013, 31:1334-1339.

16. Soulama I, Bigoga JD, Ndiaye M, Bougouma EC, Quagraine J, Casimiro PN, Stedman $\Pi$, Sirima SB: Genetic diversity of polymorphic vaccine candidate antigens (apical membrane antigen-1, merozoite surface protein-3, and erythrocyte binding antigen-175) in Plasmodium falciparum isolates from western and central Africa. Am J Trop Med Hyg 2011, 84:276-284.

17. Anderson TJ, Haubold B, Williams JT, Estrada-Franco JG, Richardson L, Mollinedo R, Bockarie M, Mokili J, Mharakurwa S, French N, et al: 
Microsatellite markers reveal a spectrum of population structures in the malaria parasite Plasmodium falciparum. Mol Biol Evol 2000, 17:1467-1482.

18. Anthony TG, Conway DJ, Cox-Singh J, Matusop A, Ratnam S, Shamsul S, Singh B: Fragmented population structure of Plasmodium falciparum in a region of declining endemicity. J Infect Dis 2005, 191:1558-1564.

19. Mu J, Awadalla P, Duan J, McGee KM, Joy DA, McVean GA, Su XZ: Recombination hotspots and population structure in Plasmodium falciparum. PLoS Biol 2005, 3:e335

20. Machado RL, Povoa MM, Calvosa VS, Ferreira MU, Rossit AR, dos Santos EJ, Conway DJ: Genetic structure of Plasmodium falciparum populations in the Brazilian Amazon region. J Infect Dis 2004, 190:1547-1555.

21. Orjuela-Sanchez P, Da Silva-Nunes M, Da Silva NS, Scopel KK, Goncalves RM, Malafronte RS, Ferreira MU: Population dynamics of genetically diverse Plasmodium falciparum lineages: community-based prospective study in rural Amazonia. Parasitol 2009, 136:1097-1105.

22. Sutton $\mathrm{PL}$, Torres $L P$, Branch $\mathrm{OH}$ : Sexual recombination is a signature of a persisting malaria epidemic in Peru. Malar J 2011, 10:329.

23. Griffing SM, Viana GM, Mixson-Hayden T, Sridaran S, Alam MT, de Oliveira AM, Barnwell JW, Escalante AA, Povoa MM, Udhayakumar V: Historical shifts in Brazilian P. falciparum population structure and drug resistance alleles. PLoS One 2013, 8:e58984.

24. Fontecha GA, Mendoza M, Banegas E, Poorak M, De Oliveira AM, Mancero T, Udhayakumar V, Lucchi NW, Mejia RE: Comparison of molecular tests for the diagnosis of malaria in Honduras. Malar J 2012, 11:119.

25. Samudio F, Santamaria AM, Obaldia N 3rd, Pascale JM, Bayard V, Calzada JE: Prevalence of Plasmodium falciparum mutations associated with antimalarial drug resistance during an epidemic in Kuna Yala, Panama, Central America. Am J Trop Med Hyg 2005, 73:839-841.

26. Haddad D, Snounou G, Mattei D, Enamorado IG, Figueroa J, Stahl S, Berzins K: Limited genetic diversity of Plasmodium falciparum in field isolates from Honduras. Am J Trop Med Hyg 1999, 60:30-34.

27. Singh B, Bobogare A, Cox-Singh J, Snounou G, Abdullah MS, Rahman HA: $A$ genus- and species-specific nested polymerase chain reaction malaria detection assay for epidemiologic studies. Am J Trop Med Hyg 1999, 60:687-692.

28. de Lamballerie X, Zandotti C, Vignoli C, Bollet C, de Micco P: A one-step microbial DNA extraction method using "Chelex 100 " suitable for gene amplification. Res Microbiol 1992, 143:785-790.

29. Excoffier $L$, Lischer HE: Arlequin suite ver 3.5: a new series of programs to perform population genetics analyses under Linux and Windows. Mol Ecol Resour 2010, 10:564-567.

30. Michalakis $Y$, Excoffier L: A generic estimation of population subdivision using distances between alleles with special reference for microsatellite loci. Genet 1996, 142:1061-1064.

31. Haubold B, Travisano M, Rainey PB, Hudson RR: Detecting linkage disequilibrium in bacterial populations. Genet 1998, 150:1341-1348.

32. Pritchard JK, Stephens M, Donnelly P: Inference of population structure using multilocus genotype data. Genet 2000, 155:945-959.

33. Evanno G, Regnaut S, Goudet J: Detecting the number of clusters of individuals using the software STRUCTURE: a simulation study. Mol ECOl 2005, 14:2611-2620.

34. Excoffier L, Smouse PE, Quattro JM: Analysis of molecular variance inferred from metric distances among DNA haplotypes: application to human mitochondrial DNA restriction data. Genet 1992, 131:479-491.

35. Rohlf F: NTSYSpc: Numerical Taxonomy System, ver. 2.20. Setauket, NY: Exeter Publishing, Ltd; 2008.

36. Leclerc MC, Durand P, de Meeus T, Robert V, Renaud F: Genetic diversity and population structure of Plasmodium falciparum isolates from Dakar Senegal, investigated from microsatellite and antigen determinant loci. Microbes Infect 2002, 4:685-692

37. Bogreau H, Renaud F, Bouchiba H, Durand P, Assi SB, Henry MC, Garnotel E, Pradines B, Fusai T, Wade B, Adehossi E, Parola P, Kamil MA, Puijalon O, Rogier C: Genetic diversity and structure of African Plasmodium falciparum populations in urban and rural areas. Am J Trop Med Hyg 2006, 74:953-959.

38. Amaratunga C, Sreng S, Suon S, Phelps ES, Stepniewska K, Lim P, Zhou C, Mao S, Anderson JM, Lindegardh N, Jiang H, Song J, Su XZ, White NJ, Dondorp AM, Anderson TJ, Fay MP, Mu J, Duong S, Fairhurst RM: Artemisinin-resistant Plasmodium falciparum in Pursat province, western Cambodia: a parasite clearance rate study. Lancet Infect Dis 2012, 12:851-858.
39. Hoffmann EH, Ribolla PE, Ferreira MU: Genetic relatedness of Plasmodium falciparum isolates and the origin of allelic diversity at the merozoite surface protein-1 (MSP-1) locus in Brazil and Vietnam. Malar J 2003, 2:24

40. Branch $\mathrm{OH}$, Sutton PL, Barnes C, Castro JC, Hussin J, Awadalla P, Hijar G: Plasmodium falciparum genetic diversity maintained and amplified over 5 years of a low transmission endemic in the Peruvian Amazon. Mol Biol Evol 2011, 28:1973-1986.

41. Gatei W, Kariuki S, Hawley W, ter Kuile F, Terlouw D, Phillips-Howard P, Nahlen B, Gimnig J, Lindblade K, Walker E, Hamel M, Crawford S, Williamson J, Slutsker L, Shi YP: Effects of transmission reduction by insecticide-treated bed nets (ITNs) on parasite genetics population structure: I. The genetic diversity of Plasmodium falciparum parasites by microsatellite markers in western Kenya. Malar J 2010, 9:353.

42. Iwagami M, Rivera PT, Villacorte EA, Escueta AD, Hatabu T, Kawazu S, Hayakawa T, Tanabe K, Kano S: Genetic diversity and population structure of Plasmodium falciparum in the Philippines. Malar J 2009, 8:96.

43. Daubersies P, Sallenave-Sales S, Magne S, Trape JF, Contamin H, Fandeur T, Rogier C, Mercereau-Puijalon O, Druilhe P: Rapid turnover of Plasmodium falciparum populations in asymptomatic individuals living in a high transmission area. Am J Trop Med Hyg 1996, 54:18-26.

44. Zhong D, Afrane Y, Githeko A, Yang Z, Cui L, Menge DM, Temu EA, Yan G: Plasmodium falciparum genetic diversity in western Kenya highlands. Am J Trop Med Hyg 2007, 77:1043-1050.

45. Conway DJ, Machado RL, Singh B, Dessert P, Mikes ZS, Povoa MM, Oduola AM, Roper C: Extreme geographical fixation of variation in the Plasmodium falciparum gamete surface protein gene Pfs48/45 compared with microsatellite loci. Mol Biochem Parasitol 2001, 115:145-156.

46. Mobegi VA, Loua KM, Ahouidi AD, Satoguina J, Nwakanma DC, Amambua-Ngwa A, Conway DJ: Population genetic structure of Plasmodium falciparum across a region of diverse endemicity in West Africa. Malar J 2012, 11:223.

47. Balloux F, Lugon-Moulin N: The estimation of population differentiation with microsatellite markers. Mol Ecol 2002, 11:155-165.

48. Gauthier C, Tibayrenc M: Population structure of malaria parasites: the driving epidemiological forces. Acta Trop 2005, 94:241-250.

49. Walliker D, Babiker H, Ranford-Cartwright L: The genetic structure of malaria parasite populations. In Malaria: parasite biology, pathogenesis, and protection. Edited by Sherman IW. Washington, DC: ASM Press; 1998.

50. Ariey F, Duchemin JB, Robert V: Metapopulation concepts applied to falciparum malaria and their impacts on the emergence and spread of chloroquine resistance. Infect Genet Evol 2003, 2:185-192.

\section{doi:10.1186/1475-2875-12-354}

Cite this article as: Larrañaga et al:: Genetic structure of Plasmodium falciparum populations across the Honduras-Nicaragua border. Malaria Journal 2013 12:354.

\section{Submit your next manuscript to BioMed Central and take full advantage of:}

- Convenient online submission

- Thorough peer review

- No space constraints or color figure charges

- Immediate publication on acceptance

- Inclusion in PubMed, CAS, Scopus and Google Scholar

- Research which is freely available for redistribution 